$\frac{4 .}{\text { DERECHO CONSTITUCIONAL Y }}$

DERECHO POLÍTICO 



\title{
CONSTITUCIÓN Y ARBITRAJE DE INVERSIONES
}

[Setting up and Arbitration of Investments]

\author{
Horacio Andaluz Vegacenteno* \\ Universidad Privada de Santa Cruz de la Sierra, Bolivia
}

\begin{abstract}
RESUMEN
De acuerdo con la legislación boliviana, el arbitraje de inversiones debe tener por sede a Bolivia. Es una regulación sui generis de esta materia. El punto de este artículo es demostrar que tal obligación no tiene su fuente en la ley de arbitraje, sino en la Constitución de Bolivia.

\section{Palabras Clave}

Arbitraje de inversiones - Centro Internacional de Arreglo de Diferencias Relativas a Inversiones - Arbitraje boliviano - Constitución boliviana.
\end{abstract}

\section{ABSTRACT}

The Bolivian legislation provides that the investment arbitration should have its seat in Bolivia. This is a sui generis regulation of this matter. This article shows that said obligation does not stem from the arbitration law, but in Bolivia's Constitution.

KeYwords
Investments Arbitration - Interna-
tional Center for Settlement of Invest-
ment Disputes - Bolivian arbitration
- Bolivian Constitution.

KEYWORDS (1)

RECIBIDO el 16 de septiembre y ACEPTADO el 7 de diciembre de 2015

* Máster en derecho internacional por la Universidad Complutense de Madrid. Profesor de teoría general del derecho y de derecho constitucional en la Universidad Privada de Santa Cruz de la Sierra, Bolivia. Correo electrónico: handaluz@cotas. com.bo 


\section{INTRODUCCIÓN}

1. Se acaba de promulgar la Ley $\mathrm{N}^{\circ} 708$ : De conciliación y arbitraje, de 25 de junio de 2015. La Ley dedica sus artículos 127 a 133 a regular el arbitraje de inversiones, definiéndolo por su carácter nacional. Establece que "serán nacionales" (artículo 129.1) y tendrán por "sede" Bolivia (artículo 129,2) es decir, dos veces lo mismo. Ya la ley dijo que es nacional el arbitraje de sede boliviana (artículo 54,I) y, a contrario, que es extranjero un laudo dictado en otra sede (artículo 120). Por consiguiente, en el lenguaje de la Ley nacionalidad y sede son sinónimos; y decir que un arbitraje nacional tendrá por sede a Bolivia es redundar. Para llegar a que el derecho boliviano condiciona la validez del arbitraje de inversiones bastaba con referirse a su sede: "un concepto puramente legal" (Corte de Apelaciones de París, asunto "Société Procédés de Préfabrication pour le Béton v. Libye”, 1998 $)^{1}$, que vincula al laudo con el sistema jurídico nacional que gobierna su validez. Puesta a un lado la reduplicación enfática de su texto, en esta materia la ley sigue a la Constitución y nada más, que al transferir al Poder Legislativo su poder de producción jurídica, lo hizo condicionando la validez de sus resultados a los límites de sus artículos 320, $\mathrm{II}^{2}$ y $366^{3}$.

2. Lo que sigue es un juicio sobre la constitucionalidad de prohibir la elección de sede en el arbitraje de inversiones. En tal orden, debe primero atribuirse significado jurídico a los artículos 320,II y 366 CPol.Bol. Una peculiaridad de la interpretación constitucional es que por todo fundamento tiene al mismo objeto materia de interpretación: la constitución. A diferencia de lo que ocurre con las fuentes ordinarias del derecho, cuya interpretación debe hacerse en coherencia con las otras fuentes que les son pares y de acuerdo con el contenido de las fuentes que condicionan su validez, la constitución es autosuficiente a tiempo de interpretarse. Queda excluido que pueda recurrirse a otra fuente para determinar su significado. Tal cosa supondría subvertir su carácter fundacional del sistema jurídico. $\mathrm{Y}$ es que si la constitución es la norma suprema del ordenamiento, lo es

${ }^{1}$ En HILl, Richard, On-line Arbitration: Issues and Solutions, en Arbitration International, 15 (1999), p. 203.

2 "Toda inversión extranjera estará sometida a la jurisdicción, a las leyes y a las autoridades bolivianas, y nadie podrá invocar situación de excepción, ni apelar a reclamaciones diplomáticas para obtener un tratamiento más favorable".

3 "Todas las empresas extranjeras que realicen actividades en la cadena productiva hidrocarburifera en nombre y representación del Estado estarán sometidas a la soberanía del Estado, a la dependencia de las leyes y de las autoridades del Estado. No se reconocerá en ningún caso tribunal ni jurisdicción extranjera y no podrán invocar situación excepcional alguna de arbitraje internacional, ni recurrir a reclamaciones diplomáticas". 
porque condiciona la validez del resto de fuentes. Por tanto, si su significado jurídico se determinase según el derecho ordinario, éste, y no ella, sería la norma suprema. En resumida coloquialidad: no puede interpretarse la constitución según lo que diga el derecho ordinario. Aparejado a lo anterior, la argumentación, como expresión del razonamiento y construcción interpretativa, es también más compleja a nivel constitucional. Es una consecuencia natural de que haya menos insumos positivos para fundar el acto interpretativo que en el derecho ordinario. Sirva esto de justificativo de las páginas siguientes, que, a pesar de su extensión, solo explicitan la comprensión de un significado jurídico (y en esto lleva la razón Gadamer al sostener que comprender es siempre interpretar $\left.{ }^{4}\right)$.

Se prescinde aquí de un análisis de política legislativa. Simplemente porque ello exorbita los límites de un juicio positivo sobre la validez del derecho ordinario.

\section{SOMETIMIENTO A LA JURISDICCIÓN BOLIVIANA:} SU LECTURA JURÍDICA (INTERPRETACIÓN DEL ARTÍCULO 320,II)

En lo aplicable directamente al arbitraje de inversiones, el artículo 320,II C.Pol.Bol. dice: "toda inversión extranjera estará sometida a la jurisdicción [...] boliviana [...]”. Esta norma prohíbe menos de lo que su texto aparenta. Para determinar su significado jurídico, acordemos: $i$ ) que el arbitraje es un derecho; ii) que las limitaciones a los derechos deben interpretarse restrictivamente; y iii) que la unidad jurisdiccional no es antinómica con el arbitraje.

1. El arbitraje es un derecho, y de fuente constitucional, porque deriva de la propiedad privada (artículo $56 \mathrm{CPol}$.Bol.). Deducir un derecho en la vía arbitral es en naturaleza jurídica un acto de disposición. Cuando la constitución garantiza la propiedad, garantiza sus facultades, esto es, la posibilidad de usar, gozar y disponer de un derecho de contenido patrimonial, que es lo definitorio de su contenido esencial (sentencia del Tribunal Constitucional 121/2012-AAC, 2 de mayo, párrafo III,4). Como siendo propietario se puede disponer de un derecho, al garantizar la propiedad se está garantizando también la libertad de contratación, como medio para ejercer dicho poder de disposición. Por tanto, derechos tales como vender, comprar o donar, que tienen todos su fuente en un contrato, enraízan en la constitución, porque todos derivan del ejercicio de la libertad de disposición como facultad comprendida en la propiedad, instrumentali-

${ }^{4}$ GadAmer, Hans-Georg; Verdad y método (traducción castellana, Salamanca, Sígueme, 1977), p. 67. 
zada, en el caso de los ejemplos, a través de un acto jurídico. Y lo mismo ocurre con el arbitraje. Que se pacte someter a la decisión de un tercero una controversia de carácter patrimonial es tan sólo ejercer la libertad de disposición que corresponde a los titulares de los derechos envueltos en tal controversia; nada más. Por ello, habiendo propiedad, hay arbitraje.

2. Siendo el arbitraje un derecho, debe interpretárselo a favor de su ejercicio. La razón de Estado republicana es instituir un gobierno de poderes limitados para garantizar los derechos, porque solo la libertad política "hace posible la única forma de convivencia entre individuos digna de un ser humano", y es la "condición previa de nuestra responsabilidad personal, de nuestra humanidad"5. Respecto de los derechos, la organización del poder es tan solo un instrumento, el medio que ha concebido la organización política para cumplir su finalidad garantista. Por tanto, el fundamento del Estado es la guarda de los derechos. Eso es lo que justifica su existencia como poder público. Nada de esto es ajeno a nuestra jurisprudencia constitucional, que ha dicho del Estado boliviano "que responde a un modelo de naturaleza eminentemente garantista, el cual se estructura bajo una premisa esencial: la eficacia máxima de los derechos fundamentales" (sentencia del Tribunal Constitucional 1112/2012-AAC, 6 de septiembre, párrafo III,2). Pues bien, si los derechos deben interpretarse a favor de su ejercicio, a contrario, sus limitaciones deben interpretarse restrictivamente. La fórmula política del Estado constitucional se positiva en una norma general que excluye de licitud la privación de conductas no prohibidas expresamente (artículo 14,IV CPol.Bol.). Y consecuencia de esta libertad general de actuación es que las limitaciones a los derechos deban interpretarse restrictivamente, porque para que lo prohibido se mantenga expreso debe rechazarse que argumentos a simile amplíen sus supuestos de hecho. Llegados a que $i$ ) el arbitraje es un derecho y ii) sus limitaciones deben interpretarse restrictivamente, el artículo 320,II debe ser tomado en el sentido menos gravoso para su ejercicio.

3. Al decir que la "inversión extranjera estará sometida a la jurisdicción [...] boliviana", el artículo 320,II está diciendo que estará "sometida" a la "potestad de impartir justicia" (artículo 178,I CPol.Bol.) que corresponde a la "función judicial" (artículo 179,I). Hay, cuando menos, dos alternativas para entender este texto: $i$ ) entender que la obligación de sometimiento a la jurisdicción boliviana queda cumplida solo si los méritos del caso son juzgados por los tribunales del país (i.e. en su jurisdicción ordinaria); ó ii) entender que hay sometimiento a la jurisdicción boliviana siempre que el

\footnotetext{
${ }^{5}$ Popper, Karl, La responsabilidad de vivir. Escritos sobre politica, historia y conocimiento (traducción castellana, Barcelona, Paidós, 1995), pp. 147 y 236.
} 
juzgamiento de méritos no exorbite la unidad que rige a la función judicial. Ambas alternativas conllevan regular un derecho: el derecho a arbitrar, nacido de la libertad de disposición. Para decidir si en la producción legislativa se ha violado un derecho, desde 2001 el Tribunal Constitucional ha adoptado la garantía del contenido esencial, como técnica para determinar el contenido de los derechos fundamentales vinculantes para el legislador. En su aplicación, excluye de regulación el núcleo esencial de los derechos, que no puede ser afectado para que no se "altere el derecho como tal" (sentencia del Tribunal Constitucional 4/2001-RDI, 5 de enero, párrafo $\mathrm{V}, 2)$. Al decir "el derecho como tal", el Tribunal Constitucional tomaba partido por la teoría absoluta del contenido esencial, que sostiene que los derechos están definidos por una específica esfera permanente, que existe como una medida preestablecida, fija y determinable en forma abstracta, como lo ha hecho al definir los derechos a la propiedad (sentencia del Tribunal Constitucional 121/2012-AAC, 2 de mayo, párrafo III.4), a una sentencia fundada (sentencia del Tribunal Constitucional 2221/2012AAC, 8 de noviembre, párrafo III.1) y al debido proceso (sentencia del Tribunal Constitucional 284/2015-AAC, 2 de marzo, párrafo III.2).

4. Junto a la teoría absoluta, la garantía del contenido esencial tiene también una vertiente relativa, en la cual "el contenido esencial es aque-

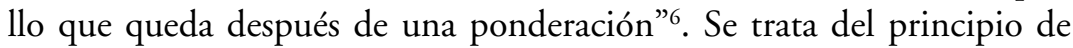
proporcionalidad, un ejercicio conceptual de ponderación de intereses contrapuestos de reiterado uso en el derecho constitucional. Como técnica para determinar el contenido de los derechos fundamentales vinculante para el legislador, la ponderación fue aplicada primero por la Corte $\mathrm{Su}$ prema de Estados Unidos. Ya en 1928 el juez Holmes había escrito, en su disidencia en el asunto "Panhandle Oil Co. v. Mississippi ex rel. Knox", que "en los días de [Marshall] no estaba reconocido, como sí lo está hoy en día, que muchas de las distinciones del derecho son distinciones de grado"7. Pero su razonamiento recién influenciaría en la Corte en las décadas siguientes, entendiéndose que una intromisión en la esfera de un derecho era innecesaria si es que la misma no era la más benigna con el derecho en cuestión (o la menos gravosa), entre todas aquellas medidas conducentes al cumplimiento de un fin constitucionalmente válido, como fue aplicado en los asuntos "Home Building \& Loan Association v. Blaisbell"' (1934), sobre moratoria hipotecaria, "Schneider v. State" (1939), sobre libertad de

${ }^{6}$ AlEXY, Robert; Teoría de los derechos fundamentales (traducción castellana, $3^{\mathrm{a}}$ reimpresión, Madrid, Centro de Estudios Políticos y Constitucionales, 2002), p. 288.

${ }^{7} 277$ U.S. 218, 223 (1928).

${ }^{8} 290$ U.S. 398 (1934).

${ }^{9} 308$ U.S. 147 (1939). 
expresión, y "Korematsu v. United States"10 (1944), sobre discriminación. En el derecho continental europeo, la aplicación pionera del principio de proporcionalidad la hizo el Tribunal Constitucional Federal alemán, recurriendo en 1958 a la ponderación en un asunto que involucraba la libertad de elegir una profesión y en el que razonó que "el legislador tenía que elegir siempre la forma de intervención que limitase los menos posible" 11 una libertad constitucional. Nada de esto es ajeno a la jurisprudencia boliviana, que a la vez que se ha mantenido aferrada a la teoría absoluta del contenido esencial, también ha dado aplicación a su vertiente relativa, como lo ha hecho al declarar la inconstitucionalidad del delito de desacato, por tratarse de una intromisión "desproporcionada" en la libertad de expresión (sentencia del Tribunal Constitucional 1250/2012-AIC, 20 de septiembre, párrafo III,3,1).

5. Que el Tribunal Constitucional se haya decantado, a la vez, por la garantía del contenido esencial (teoría absoluta) y por el principio de proporcionalidad (teoría relativa) es constitucionalmente válido, porque ambos son definiciones operativas del concepto jurídico de inviolabilidad de los derechos (artículo 13.I C.Pol.Bol.). Hasta acá el marco que debe usarse para el enjuiciamiento constitucional de las dos alternativas dadas. Enjuiciada la primera según la teoría absoluta, entender que la obligación de sometimiento a la jurisdicción boliviana queda cumplida solo si los méritos del caso son juzgados por los tribunales del país (i.e. en su jurisdicción ordinaria) es inconstitucional, por su velada privación del derecho a arbitrar. Como el contenido esencial de este derecho consiste en la libertad de decidir si una controversia se somete a la jurisdicción ordinaria o al arbitraje, la primera alternativa supone vaciarlo de contenido, excluyendo de antemano la prerrogativa de someter una controversia a arbitramento allí donde la constitución no la ha excluido expresamente. Enjuiciada según el principio de proporcionalidad, la primera alternativa es por igual violatoria del derecho a arbitrar. La causa ya no es el vaciamiento en sí mismo de su contenido esencial, sino la desproporción entre la medida adoptada para dar cumplimiento al artículo 320,II y el derecho a arbitrar. Como la medida que adopta la primera alternativa supone que el juzgamiento de méritos quede a cargo exclusivamente de la jurisdicción ordinaria, la decisión de someter una controversia a arbitramento estaría completamente excluida. Con esto, la primera alternativa se configura como una intromisión innecesaria en la libertad de disposición. Y ya que

${ }^{10} 323$ U.S. 214, 216 (1944).

${ }^{11}$ BVerfGE 7, 377, en SCHWABE, Jurgen (compilador), Jurisprudencia del Tribunal Constitucional Federal alemán ( $1^{\text {a }}$ edición, Montevideo, Fundación Konrad Adenauer, 2009), p. 322. 
la "necesidad" de la intromisión en la esfera de un derecho es un concepto relacional, véase que la segunda alternativa es la más benigna con el derecho a arbitrar, haciendo de la primera la menos benigna o la más gravosa y, por tanto, inconstitucional.

6. La segunda alternativa entiende que hay sometimiento a la jurisdicción boliviana siempre que el juzgamiento de méritos no exorbite la unidad que rige a la función judicial. Hay unidad jurisdiccional cuando la justicia que emana del pueblo (artículo 178.I C.Pol.Bol.) sólo la ejerce el órgano por él delegado. Dice de su monopolio por parte del Estado y de su encargo al Poder Judicial. Arraiga en la división de poderes. Viene de la prohibición de delegación de las competencias públicas (artículo 12,III). Está en la declaración de unicidad de la función judicial (artículo 179,I) y en la prohibición de tribunales de excepción (como organización, artículo 180,III; como derecho, artículo 120,I). El Poder Judicial está formado por una pluralidad de órganos independientes entre sí (jueces y tribunales). Forman una unidad si sus decisiones son revisables, directa o indirectamente, por un único órgano supremo. En los sistemas que vienen del "common law", la unidad la dan sus cortes supremas. Aunque en los niveles inferiores la jurisdicción es especializada, la competencia de las cortes supremas no queda cercenada. El único alto tribunal son ellas. En los sistemas que evolucionaron de la Revolución Francesa, la unidad la dan sus tribunales constitucionales. Acá no hay diferencia con los sistemas del "common law", mientras que en la tradición romano-germánica la defensa de la constitución se encarga a un tribunal especializado, el mundo anglo-americano la confía a sus cortes supremas. En ambos casos la unidad de la jurisdicción viene de la unidad de la norma fundacional del sistema jurídico. Sólo puede venir de allí. Esa norma es la constitución. Y la unidad jurisdiccional es la representación funcional de su defensa. No hay decisión judicial que no pueda ser enjuiciada por violaciones constitucionales: todas están sujetas al imperio de la constitución. Y, por tanto, lo están a la competencia de su custodio: las decisiones de la jurisdicción ordinaria y de sus jurisdicciones especializadas, de la jurisdicción militar (artículo 180,III), de la jurisdicción agroambiental (artículo 186) y de la jurisdicción indígena originario campesina (artículo 190,II) son todas enjuiciables por el Tribunal Constitucional. Llegados acá, no hay antinomia entre la unidad jurisdiccional y el arbitraje, porque todo acto de aplicación del derecho está sujeto a las garantías constitucionales para el ejercicio de la jurisdicción y, por tanto, a la competencia del Tribunal Constitucional para su enjuiciamiento. Lo contrario sólo sería explicable si el arbitraje exorbitara el sistema constitucional. No siendo así, es simplemente insostenible. Por tanto, aplicado al arbitraje, la unidad jurisdiccional significa 
la competencia que tiene el Poder Judicial para enjuiciar la validez de las decisiones arbitrales. Y si resulta que el arbitraje de inversiones es de sede boliviana (artículos 129,1 y 129,2 de la Ley $\mathrm{N}^{\circ} 708$ ), el sistema jurídico que gobierna la validez del laudo es el nacional y la jurisdicción competente para decidir sobre su nulidad es también la boliviana. Por tanto, al entender que hay sometimiento a la jurisdicción boliviana siempre que el juzgamiento de méritos no exorbite la unidad que rige a la función judicial, la segunda alternativa asegura que "toda inversión extranjera est[é] sometida a la jurisdicción [...] boliviana" (artículo 320,II C.Pol.Bol.), porque está sometida a su "potestad de impartir justicia" (artículo 178,I C.Pol.Bol.), que corresponde a la "función judicial" (artículo 179,I) a través del recurso de nulidad del laudo.

7. Enjuiciada la segunda alternativa según la garantía del contenido esencial, esta vez el derecho a arbitrar no queda desprovisto de sustancia. Como la competencia de la jurisdicción boliviana para resolver el recurso de nulidad contra el laudo es consecuencia de la sede del arbitraje, para que el sometimiento a la jurisdicción boliviana quede asegurado, debe asegurarse que la sede sea Bolivia. Esto es lo que hace la Ley 708 (artículos 129,1 y 129,2). Al reglar que el arbitraje de inversiones será nacional (artículo 129,1) y tendrá por sede Bolivia (artículo 129,2) está reservando la competencia de resolver el recurso de nulidad contra el laudo al Poder Judicial boliviano. Con esto, hace dos cosas: i) somete a la jurisdicción boliviana el enjuiciamiento de la validez de las decisiones arbitrales; y ii) regula el derecho a arbitrar sin cercenarle su esencia. La decisión de someter una controversia patrimonial a arbitramento sigue en la esfera protegida de la libertad de disposición, siendo lícito decantarse por someterse a la jurisdicción ordinaria o al arbitraje. Lo único que se ha regulado, prohibiéndoselo, es la decisión sobre la sede del arbitraje. Esta decisión, con importante que es, es de naturaleza accesoria respecto al derecho a arbitrar. Mientras que decidir someter una controversia a arbitramento hace a la esencia de este derecho, la elección de la sede está en su periferia. Por tanto, es constitucionalmente válido que la decisión sobre la sede esté sometida a una regulación imperativa. Es así porque no importa privación del derecho a arbitrar, sino que lo presupone. Y si se somete la segunda alternativa a un juicio de proporcionalidad, el resultado también es su constitucionalidad. Esta vez el fundamento no viene de preservar el contenido esencial del derecho, sino de la proporcionalidad entre la medida de cumplimiento del artículo 320,II C.Pol.Bol. y la intromisión en la esfera de la libertad de disposición. $\mathrm{Al}$ reservar, a través de la sede, la competencia del recurso de nulidad a los tribunales bolivianos a cambio de prohibir la elección de una sede distinta a la nacional, la segunda alternativa se configura como 
una intromisión "necesaria” en la esfera de la libertad de disposición, porque es la más benigna para cumplir el fin constitucionalmente válido de sometimiento a la jurisdicción boliviana. A contrario: no hay manera menos invasiva del derecho a arbitrar que prohibir la elección de sede para dar cumplimiento al artículo 320,II. Por tanto, el significado jurídico de este artículo consiste en reservar para el Poder Judicial el enjuiciamiento en vía de nulidad de los laudos producidos en arbitrajes de inversiones. Así determinado su significado, su texto prohíbe menos de lo que efectivamente norma. Hasta acá la interpretación del artículo 320,II.

\section{Prohibición DE ARbITRAJE INTERNACIONAL: SU LECTURA JURÍDICA (INTERPRETACIÓN DEL ARTÍCULO 366)}

1. Pasemos ahora al artículo 366 C.Pol.Bol. Éste, en lo aplicable directamente al arbitraje de inversiones, dice: "las empresas extranjeras que realicen actividades en la cadena productiva hidrocarburifera en nombre $y$ representación del Estado [...] no podrán invocar situación excepcional alguna de arbitraje internacional [...]". Pasa acá lo mismo que con el artículo 320,II: la norma prohíbe menos de lo que aparenta su texto. Pero con una agravante: hay que liberar a la norma de la literalidad de su propio texto para que produzca algún efecto jurídico.

Por su ámbito de vigencia personal, el artículo 366 se dice aplicable a "todas las empresas extranjeras que realicen actividades en la cadena productiva hidrocarburifera en nombre y representación del Estado". Acá está el problema. Si solo Yacimientos Petrolíferos Fiscales Bolivianos es: i) la "única [empresa] facultada para realizar las actividades de la cadena productiva de hidrocarburos y su comercialización" (artículo 361,I C.Pol.Bol.); y ii) por consecuencia de tal calidad, es la única autorizada a "suscribir contratos [...] con empresas públicas, mixtas o privadas, bolivianas o extranjeras, para que dichas empresas, a su nombre y representación, realicen determinadas actividades de la cadena productiva" (artículo 362,I), es constitucionalmente imposible que una empresa extranjera participe en la cadena productiva hidrocarburífera "en nombre y representación del Estado" (artículo 366). A contrario: la única posibilidad para que participase sería que el Estado incumpla su propia constitución y contrate directamente con ella, rehusando la participación obligatoria de Yacimientos Petrolíferos Fiscales Bolivianos. Hasta acá, la literalidad del artículo 366 sustrae su aplicación a sus propios sujetos normativos. Por tanto: $i)$ gramaticalmente el artículo 366 no produce efecto alguno (i.e. no hay sujeto al cual aplicarla); y ii) produce, más bien, una antinomia con el artículo 361,I.

2. Ya para 1803 el juez Marshall había importado para la interpretación 
constitucional una regla tan antigua como que ya estaba inscrita en el Digesto de Justiniano (siglo VI) y que manda que "en casos ambiguos, lo más conveniente es aceptar que la cosa de que se trata más bien sea válida a que perezca"12, razonando por la Corte que "no puede presumirse que cláusula alguna de la constitución esté pensada para no tener efecto" (Corte Suprema de Estados Unidos, asunto "Marbury v. Madison", 1803) ${ }^{13}$. La corrección racional de esta regla la dota de la universalidad suficiente para aplicarla a cualquier fuente del derecho. Pero en el caso de la Constitución boliviana, su aplicación debe sortear primero su artículo 196,II.

3. El artículo 196,II es una cláusula de interpretación: "En su función interpretativa, el Tribunal Constitucional Plurinacional aplicará como criterio de interpretación, con preferencia, la voluntad del constituyente, de acuerdo con sus documentos, actas y resoluciones, asi como el tenor literal del texto". Las reglas de interpretación positivadas son meta normas (fuentes). Ellas, al reglar la reconstrucción interpretativa de las disposiciones jurídicas, están sujetando sus condiciones de validez al criterio de interpretación positivado por la regla. Y aunque por su ámbito de aplicación personal el artículo 196,II sólo vincula al Tribunal Constitucional, su cumplimiento es una exigencia de razonabilidad práctica, que dicta que al interpretar la constitución se la interprete según los criterios que usará el Tribunal para juzgar la corrección de tal interpretación. La locución adverbial "con preferencia” es la que da al artículo 196,II su significado jurídico, más allá del mandato literal de preferir la "voluntad del constituyente" (interpretación histórica) y el "tenor literal del texto" (interpretación gramatical). No dice que preferirá un criterio al otro, sino que preferirá ambos: "con preferencia" uno "así como" el otro, que es lo mismo que "con preferencia” uno "y" el otro. La determinación de su significado jurídico es más compleja que la lectura de su texto. Si ambos criterios deben aplicarse "con preferencia", otros criterios también pueden aplicarse, pero sin tal carácter preferente. Por el operador deóntico que contiene, "con preferencia" no es una prohibición, sino un permiso: autoriza a servirse de otros criterios, frente a los cuales tienen preferencia los mencionados en la cláusula. Por tanto, la cláusula de interpretación no confina a la aplicación de sus criterios, sino que obliga a justificar su inaplicación, cuando existan razones excluyentes $^{14}$ para hacerlo (razones que justifiquen que, a pesar de inaplicarlos, no

${ }^{12}$ Dig. 34,5,12 : "Quoties in ambigua oratio est, commodissimum est, id accipi, quo res, de qua agitar, magis valeat quam pereat".

135 U.S. (1 Cranch) 137, 174 (1803).

${ }^{14} \mathrm{El}$ concepto de "razones excluyentes para la acción" es de Raz, Joseph; Practical Reason and Norms (reimpresión, Nueva York, Oxford University Press, 2002), pp. 35 ss. 
se está incumpliendo la constitución). Hasta aquí se extiende su sentido normativo.

4. En este punto, hay dos razones para rehuir la interpretación gramatical del artículo 366: $i$ ) Cuando el texto no conduce a ningún resultado, como es el caso acá, los límites naturales de la interpretación gramatical actúan como razones excluyentes de la obligación de aplicarla. Cada criterio de interpretación está limitado por las propias razones que lo justifican como tal y ninguno está libre de no conducir a ningún resultado, sucumbiendo por agotamiento interno. Cuando un criterio queda rendido por consunción, son sus propias limitaciones las que devuelven al intérprete la plenitud de su libertad hermenéutica, debiendo prescindir de él. Y esto es lo que ocurre acá, donde "el tenor literal del texto" sustrae la aplicación del artículo 366 a sus propios sujetos normativos; ii) Cuando el texto es antinómico con otras normas constitucionales, la unidad del sistema jurídico es también razón excluyente suficiente para no interpretarlo gramaticalmente. El sistema jurídico forma una unidad en la medida que la validez de la pluralidad de sus normas puede ser reconducida hacia una única norma mayor como fuente universal de validez. Para que un sistema jurídico forme una unidad, la norma que le provee validez debe también formar una unidad: lo que se traduce en que el seno de la constitución no puede albergar antinomias (principio de unidad de la constitución). Por tanto, una interpretación constitucional posible es aquella que se justifica en la unidad de la constitución. A contrario: debe rechazarse aquella interpretación que quiebre la unidad del sistema, aun cuando fundada en el "tenor literal del texto". Y tal es el caso acá, donde la literalidad del artículo 366 es antinómica con el artículo 361,I.

5. Basta con leer el artículo 366 según los artículos 361, I y 362,I para reconstruir interpretativamente su sujeto normativo. Si ya el primero dijo que Yacimientos Petrolíferos Fiscales Bolivianos es la "única [empresa] facultada para realizar las actividades de la cadena productiva de hidrocarburos y su comercialización", y si ya el segundo la autorizó a "suscribir contratos [...] con empresas públicas, mixtas o privadas, bolivianas o extranjeras, para que dichas empresas, a su nombre y representación, realicen determinadas actividades de la cadena productiva", al referirse a "las empresas extranjeras que realicen actividades en la cadena productiva hidrocarburifera en nombre y representación del Estado", el artículo 366 se está refiriendo a las empresas que lo hagan en nombre y representación de Yacimientos Petrolíferos Fiscales Bolivianos, porque sólo esta empresa se halla facultada para participar en las actividades de la cadena productiva y a contratar a su nombre y representación los servicios de terceros para la ejecución de dichas actividades. Esta es una interpretación sistémica, fundada en la coherencia 
formal y material entre los artículos que pertenecen a una misma fuente (la constitución) y que comparten el mismo contenido (hidrocarburos).

6. Agotada la elaboración a que obligaba la sustracción literal del sujeto normativo, toca determinar el significado jurídico de la prohibición de "invocar [...] arbitraje internacional". Como la fórmula política del Estado constitucional se positiva en una norma general que excluye de licitud la privación de conductas no prohibidas expresamente (artículo 14,IV C.Pol. Bol.), si lo prohibido es el arbitraje internacional, a contrario, el arbitraje nacional está permitido. Pero esto es cambiar una imprecisión por otra: ya que el artículo 366 no define el carácter internacional del arbitraje, no puede excluirse de su definición a su antónimo. Lo que sí puede hacerse es leer el artículo 366 en conjunto con el artículo 320,II. La razón: ya que una "empresa extranjera" (artículo 366) es una "inversión extranjera" (artículo 320.II), hay entre ambas categorías una relación de identidad, donde "inversión extranjera" es el género y "empresa extranjera [de hidrocarburos]" la especie, por lo que es atendible al pensamiento jurídico que las reglas del género sean por igual aplicables a sus especies, salvo regla expresa en contrario.

7. Ya está visto que el significado jurídico del artículo 320,II consiste en reservar al Poder Judicial la competencia de enjuiciar en vía de nulidad los laudos producidos en arbitrajes de inversiones. Por lo tanto, el arbitraje excluido de la prohibición del artículo 366 será aquel que no cumpla con dicha reserva. Y ya que la competencia para declarar la nulidad del laudo es consecuencia de la sede del arbitraje, solo se incumpliría con la reserva si es que la sede del arbitraje no fuera Bolivia. La razón: la sede es simplemente la vinculación del laudo con el sistema jurídico que gobierna su validez, de ahí que sean los tribunales de dicho sistema los competentes para juzgar su nulidad. Llegados acá, si leído según el artículo 320,II lo permitido por el artículo 366 es el arbitraje de sede boliviana, lo que su texto debió prohibir es el arbitraje extranjero: aquel gobernado por un sistema jurídico que no sea el nacional. Al prohibir el "arbitraje internacional", su texto se contradijo a sí mismo: si está normando el arbitraje entre "empresas extranjeras" y Yacimientos Petrolíferos Fiscales Bolivianos (i.e. una empresa boliviana), se trata de un arbitraje con conexiones a otros sistemas jurídicos y, por tanto, convencionalmente calificado como internacional, ya sea por la nacionalidad o el domicilio de las partes, como sería el caso acá, o por la materia controvertida, el lugar de cumplimiento de las obligaciones o el lugar que guardase la relación más estrecha con el objeto de la controversia. Al prohibir el arbitraje internacional, el artículo 366 quiso significar que prohibía el arbitraje en sede extranjera. Este es el significado jurídico de su prohibición. 
8. En consecuencia, la Ley $\mathrm{N}^{\circ} 708$, al disponer que el arbitraje de inversiones sea nacional (artículo 129,1) y de sede boliviana (artículo 129,2), aunque redundante, no hizo más que normar la materia de acuerdo con la Constitución, que: $i$ ) reserva para la jurisdicción boliviana la decisión de nulidad de los laudos de inversiones (artículo 320,II); y ii) prohíbe que las inversiones foráneas en hidrocarburos se arbitren en sede extranjera (artículo 366). Por tanto, la obligación de arbitrar con el Estado en su propia sede, si cuestionable, no lo es como decisión de política legislativa, sino como obligación de fuente constitucional.

\section{Prohibición de RECLAMACIONES DIPLOMÁTICAS: SUS EFECTOS}

1. Es común a los artículos 320,II y 366 C.Pol.Bol. la prohibición de "reclamaciones diplomáticas" (cláusula Calvo). Al prohibirlas, la Constitución apunta a atajar una técnica de adjudicación propia del derecho internacional: la protección diplomática. Respecto de ésta, el arbitraje de inversiones es tan solo la respuesta de derecho positivo a su ineficacia connatural a su pertenencia a un orden de técnica de regulación descentralizada. Las reglas de competencia que autorizan a identificar el derecho válido, aplicarlo y modificarlo son descentralizadas en el derecho internacional, haciendo que el propio sujeto sea, a la vez, autoridad normativa de este sistema. Esto es lo que ocurre en la protección diplomática. Es el propio Estado perjudicado quien califica la ilicitud internacional de la acción de su par. Como tal, es una técnica de defensa de los derechos del propio Estado, reconduciéndose las violaciones al orden internacional dañosas para sus súbditos al "derecho que tiene a hacer respetar el derecho internacional en la persona de sus nacionales" (Corte Permanente de Justicia Internacional, asunto "The Mavrommatis Palestine Concessions, Grecia v. Turquía”, 1924) ${ }^{15}$. En la medida que es un derecho del Estado, su ejercicio queda librado a su discreción, pudiendo muy bien decidirse por no defender los derechos de sus súbditos (si esto, a su vez, le genera responsabilidad por dejar desprotegidos a sus nacionales es un asunto que depende de cada derecho interno). Pero, si se decide a defenderlos: i) como "el vínculo de la nacionalidad entre el Estado y el individuo es el único que da al Estado el derecho de protección diplomática" (Corte Permanente de Justicia Internacional, asunto "Panevezys-Saldutiskis Railway, Estonia v. Lituania”, 1939) ${ }^{16}$, el inversionista afectado debe ser nacional del Estado que reclama; ii) en este sentido, si el inversionista es una sociedad comercial,

\footnotetext{
${ }^{15}$ PCIJ, Series A, No. 5, p. 12.

${ }^{16}$ PCIJ, Series A/B, No. 76, p. 4.
} 
"el derecho a ejercer la protección diplomática de una sociedad corresponde al Estado bajo cuyas leyes se ha constituido y en el que la misma tiene su sede" (Corte Internacional de Justicia, asunto "Barcelona Traction, Light and Power Company, Bélgica v. España”, 1970) ${ }^{17}$; iii) si el inversionista es un accionista de una sociedad comercial, la protección del Estado de su nacionalidad solo se ejerce a título excepcional: por un lado, si es que el hecho reclamado ha lesionado los derechos del accionista en cuanto tal, y, por otro lado, si es que la sociedad ha dejado de existir; iv) y, para todos los supuestos en general, el inversionista debe haber "sometido la esencia de la [reclamación] a las jurisdicciones competentes y haber perseverado, sin éxito, tan lejos como lo permitan las leyes y los procedimientos locales" (Corte Internacional de Justicia, asunto "Elettronica Sicula, Estados Unidos v. Italia", 1989) ${ }^{18}$, lo que es igual a agotar infructuosamente todos los medios de defensa útiles o efectivos existentes en el ordenamiento del Estado sindicado de responsabilidad.

2. La prohibición de reclamaciones diplomáticas viene desde las reformas constitucionales de 1938 (artículo 18) ${ }^{19}$, pero sus efectos son, cuando menos, dudosos: $i$ ) una norma de derecho interno que trate de excluir el ejercicio de la protección diplomática con base en la renuncia previa del inversionista es vana respecto del derecho internacional general; ii) si la protección diplomática es un derecho del Estado, un inversionista no puede renunciar al ejercicio de un derecho que no es suyo; iii) aún si se asume que solo renuncia al derecho propio de reclamar ante su Estado, igual es una renuncia ineficaz, porque tal derecho lo otorga el sistema jurídico de su nacionalidad y solo ante dicho sistema puede ser renunciado; iv) y aun asumiendo que la renuncia fuese plenamente eficaz, la misma no alcanzaría a los hechos ilícitos del Estado en contra de la defensa del inversionista en su jurisdicción interna, como el supuesto de denegación de justicia, excluido de renuncia en las reformas de 1938, porque tal cosa supondría institucionalizar la tropelía como regla de convivencia, en disenso con la pretensión de corrección que distingue al derecho, y su "dimensión ideal necesaria que lo saca del ámbito de la pura contingencia" ${ }^{\text {, }}$, de la fuerza bruta.

3. Como el derecho es un epifenómeno de la cultura, la política nor-

${ }^{17}$ ICJ Reports (1970), p. 3

${ }^{18}$ ICJ Reports (1989), p. 15

19 "Los súbditos o empresas extranjeras están, en cuanto a la propiedad, en la misma condición de los bolivianos, sin que en ningún caso puedan invocar situación excepcional ni apelar a reclamaciones diplomáticas, salvo caso de denegación de justicia".

${ }^{20}$ ALEXY, Robert; El concepto y la validez del derecho (traducción castellana, Barcelona, Gedisa, 1994), p. 33. 
mativa es a la vez reactiva y proyectiva. Reactiva, porque responde a una necesidad normativa no satisfecha por el orden en vigor. Y proyectiva, porque al dar una respuesta a tal necesidad propone un estado de cosas normativamente deseable. Esto explica que la práctica vaya en dirección distinta a la protección diplomática, escapando de los riesgos de su ineficacia, por parte del inversionista, y evitando contaminar sus relaciones internacionales con una eventual controversia con un particular, por parte de los Estados, innovando su relacionamiento mutuo a través del arbitraje. Con independencia de su fuente positiva, el arbitraje de inversiones excluye el ejercicio inmediato de la protección diplomática por parte del Estado de la nacionalidad, al estar obligado el inversionista a recurrir previamente a la vía arbitral. Pero subsiste el ejercicio mediato de la protección diplomática, ya que en caso en que el Estado vencido no honre de buena fe el laudo dictado en su contra, el Estado de la nacionalidad puede reclamarle su incumplimiento. Tal es la hipótesis legislada en el Convenio sobre arreglo de diferencias relativas a inversiones entre estados y nacionales de otros Estados ("Convenio de Washington", 1965, artículo 27,1)21, denunciado por Bolivia ${ }^{22}$, que codifica la convicción de obligatoriedad que la práctica de la protección diplomática ha producido en el derecho internacional general. Que tal hipótesis haya sido codificada significa su preexistencia como norma de derecho internacional general. Por tanto, si bien no por la fuerza de un tratado, por la fuerza del derecho internacional consuetudinario los Estados por igual pueden reclamar por las violaciones al derecho internacional en las personas de sus inversionistas, cuando los medios previstos para zanjar sus controversias fracasen.

\section{BIBLIOGRAFÍA}

AlEXY, Robert; El concepto y la validez del derecho (traducción castellana, Barcelona, Gedisa, 1994).

AlEXY, Robert; Teoría de los derechos fundamentales (traducción castellana, $3^{\text {a }}$ reimpresión, Madrid, Centro de Estudios Políticos y Constitucionales, 2002).

GADAMER, Hans-Georg; Verdady método (traducción castellana, Salamanca, Sígueme, 1977).

21 "Ningún Estado Contratante concederá protección diplomática ni promoverá reclamación internacional respecto de cualquier diferencia que uno de sus nacionales y otro Estado Contratante hayan consentido en someter o hayan sometido a arbitraje conforme a este Convenio, salvo que este último Estado Contratante no haya acatado el laudo dictado en tal diferencia o haya dejado de cumplirlo".

${ }^{22}$ De acuerdo con su artículo 71, la denuncia de Bolivia al "Convenio de Washington" tuvo efecto el 3 de noviembre de 2007. 
HiLl, Richard; On-line Arbitration: Issues and Solutions, en Arbitration International, 15 (1999).

POPPER, Karl, La responsabilidad de vivir. Escritos sobre politica, historia y conocimiento (traducción castellana, Barcelona, Paidós, 1995).

Raz, Joseph; Practical Reason and Norms (reimpresión, Nueva York, Oxford University Press, 2002).

SCHWABE, Jurgen (compilador), Jurisprudencia del Tribunal Constitucional Federal alemán (1ª edición, Montevideo, Fundación Konrad Adenauer, 2009). 